\title{
MUTUAL MOTHER-PUP RECOGNITION IN GALÁPAGOS FUR SEALS AND SEA LIONS: CUES USED AND FUNCTIONAL SIGNIFICANCE
}

\author{
by
}

\author{
FRITZ TRILLMICH ${ }^{\text {) }}$
}

(Max-Planck-Institut für Verhaltensphysiologie, Seewiesen, W.-Germany)

Mothers of colonially breeding seals regularly reunite promptly with their own pups after sometimes long absence at sea. This performance is astonishing as especially older otariid young move over considerable distances within the colony during the absence of their mothers and often gather in pods of about equal age. Individual recognition seems the only plausible hypothesis explaining the necessary discriminatory performance. Although experimental evidence on individual recognition in seals is almost nonexistant (except in the elephant seal, Mirounga angustirostris, Petrinovich, 1974), most authors agree that mothers take far the more active part in recognition, and that young pups react indiscriminately to any female approaching with a Pup Attraction Call (PAC) (Bartholomew, 1959; Fogden, 1971; Laws, 1956; Peterson \& Bartholomew, 1967 (for pups less than two months of age), Petrinovich, 1974; McNab \& Crawley, 1975). Other authors (Rand, 1967; Sandegren, 1970; Peterson \& Bartholomew, 1967 (for pups older than two months)) assume that pups too contribute specifically towards a reunion. The latter appears far more plausible as pups expose themselves to serious danger when inadvertently approaching a strange, and sometimes violently aggressive female (Le BoEuf \& Briggs, 1977; Fogden, 1971; Peterson \& Bartholomew, 1967). Consequently one should expect strong selection on pups to develop a recognition system allowing early learning of the specific signals emitted by the mother.

1) I would like to thank J. Lamprecht, C. Rechten, H.-U. Reyer, M. TABorsky and W. Wickier for helpful discussions and J. Cilio, D. Nakashima, D. Limberger and K. TriLlmich for invaluable help during the field work. C. Kasche and H. Kacher expertly prepared the figures and P. RECHTEN kindly corrected my english. It is a pleasure to acknowledge the support of the Charles Darwin Station through its directors C. MACFArLAND and H. N. Hokck and of the Galápagos National Park through its Intendent M. Cifuentes. This is contribution No 311 of the Charles Darwin Research Station.

Dedicated to Wolfgang Wickler on the occasion of his 50th birthday. 
Indeed, during a study of the Galápagos fur seal (Arctocephalus galapagoensis) and Galápagos sea lion (Zalophus californianus wollebaeki), evidence accumulated indicating mutual recognition between mother and pup. Which cues could convey sufficient information to code the identity of the signaller? There are no indications that visual cues are involved and olfactory cues can function only in close proximity under the conditions in a crowded otariid colony. The most useful sense for identification from a distance is hearing. Therefore, and because acoustical cues lend themselves to experimentation through playback, these were explored first.

Background information on the biology of the two species. The Galápagos fur seal.

This fur seal reproduces on Fernandina (the westernmost of the Galápagos islands) from August until November. Females nurse the pups for two or more years. If the mother does not bear another pup, even animals over three years old may suckle occasionally. The female remains with a newborn for about one week. Later on she regularly goes off to feed and returns to her pup every day or every few days and stays with it for half a day to three days (Trillmich \& Mohren, 1981). The young moult into adult fur when they are about four months old. They lose their milk teeth between the fifth and twelfth month. After this and increasingly during their second and third years they begin to hunt for themselves and become independent of their mothers.

The Galápagos sea lion.

This sea lion reproduces mainly during the cooler season (approx. May-January). The timing varies somewhat from island to island. Females nurse one pup until the next is born. Some mothers will then nurse pup and yearling together, rarely for more than a year. As long as the mother does not bear another pup she may continue nursing the young for up to three years. The mother stays with the newborn for 4-7 days after birth. She then regularly leaves to feed, coming back almost every night to suckle the pup. The young moult their pup fur when about 4-5 months old. Shortly after the moult they begin to hunt for themselves, thus becoming increasingly independent of their mothers' milk.

\section{METHODS}

Marking of seals.

Pups were marked soon after birth by cutting symbols into the fur of their backs. Female fur seals were marked either by fur clipping or fur bleaching with Clairol Born 
Blond, unless otherwise easily recognizable by flipper scars or shark bite patterns in their pelts. Female sea lions were usually recognized by a combination of scars and voice characteristics. Only a few were marked additionally by fur clipping.

\section{Sites and times of observations and experiments.}

All fur seal observations and playback experiments were made at Cabo Hammond, Fernandina, in Dec. 1976, Feb. 1978, and Aug.-Nov. 1977 and 1979.

Most of the sea lion observations and playback experiments were done in June, July and Sept. 1976, and June and July 1977 on Santiago, some in Oct. and Nov. 1976 on Càmaño islet, close to Santa Cruz, and in Jan. and Feb. 1977 on Española.

\section{Recording and analysis of calls.}

Recordings were made from a distance of $1.5 \mathrm{~m}$ using a Uher 4200 portable tape recorder at tape speed $9.5 \mathrm{~cm} / \mathrm{sec}$ and a Sennheiser MKH T415 directional microphone. Animals were well accustomed to observers and showed no disturbance when approached closely for the tape recording.

To differentiate details at the lower frequencies, calls were sonagraphed using the logarithmic frequency scale of the Kay Electrics Sonagraph $6061 \mathrm{~B}$ at the narrow filter setting. Frequencies were calibrated using pure tones at $100 \mathrm{~Hz}$ intervals and measurements of frequencies in calls were made to the nearest $20 \mathrm{~Hz}$ in the range up to $1000 \mathrm{~Hz}$. Differences between the dominant frequencies of calls of different females were tested with the Mann-Whitney U-Test (two tailed).

\section{RESULTS}

Observations suggesting mutual mother-pup recognition.

The fur seal.

Mother and pup are in very close and intensive contact during the first days of a pup's life and have ample opportunity to learn each other's characteristics. During birth the mother already sniffs at the pup's head, back, and anogenital region, occasionally giving a peculiar drawn-out call which I term the Pup Contact Call (PCC; see below for description of calls). Whenever the pup moves away from its mother it is called back with PACs (Pup Attraction Calls).

Pups begin to call within minutes of birth, and spend more time calling during their first day of life than ever later (Fig. 1). For 2 pups time spent calling was measured, using time-budget analysis, when they were 1,3 , $5,9 / 12$, and 30 days old, and was found to be negatively correlated with age (Spearman rank correlation; $\mathrm{p}=0.05$ and $\mathrm{p}=0.01$ ). Calling activity of mothers, measured on the same days, appeared to wane correspondingly; but the Spearman rank correlation reaches statistical significance in one case only $(p=0.05)$.

That the mother recognizes her young after a few hours of these intensive interactions is shown by natural experiments where mother and pup were separated within 24 h of birth: 1) Even when their own pup was in- 


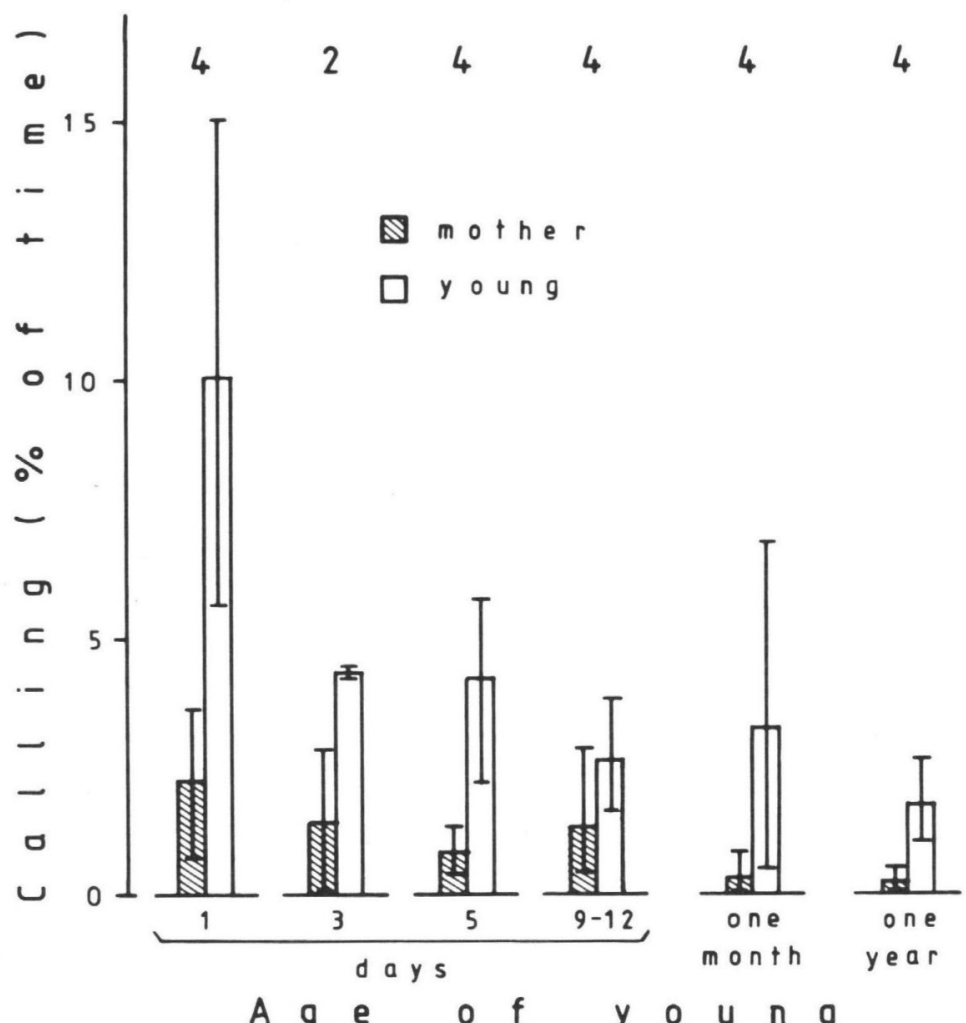

Fig. 1. Calling activity of fur seal mothers and young at various ages of the young. Time budget data were recorded using instantaneous sampling every minute on the minute throughout the day. The graph is based on 24.6-47.2 h of observation for a given age. No. of animals observed indicated above the columns. The bars show the total range of values observed at each age.

active and hidden, mothers behaved aggressively towards all other pups, even neonates. 2) After female fighting in which pups became exchanged, mothers reclaimed their own pups (3 cases). 3) Sometimes newborn pups fall into holes between boulders where they can neither be seen nor sniffed at. (This causes 1-5\% mortality of neonates deaths according to local habitat structure.) As long as such pups keep calling occasionally, their mothers stay near these holes, sometimes for days, calling PACs and trying - very often successfully - to retrieve them. Even if such a female cannot save her pup she never adopts a strange one, even if lone pups a few days old are nearby. These observations document the rapid formation, specificity and irreversibility of the mother-young bond. 
When a female returns from a foraging trip she gives PACs and moves up towards the site where she has left her pup. If strange pups approach her she may threaten or gently bite them, but some females even chase fleeing pups, bite hard and even toss them. This was twice observed to lead to the death of a pup. When mother and pup meet the pup may make an olfactory check (nose contact with the mother's nose or fur) while the mother invariably sniffs at the pup. This check appears to provide the decisive cue for acceptance or rejection of a pup, as at this stage females often rebuff strange pups. As the young grow older mothers do less searching and calling and the reestablishment of contact becomes increasingly the task of the young.

The best evidence for mother-recognition by pups comes from observations of pups in a playgroup. When a mother returns from a foraging trip and calls, her own pup is generally the only one in the group that responds at once to her PACs. But even healthy well-fed pups occasionally approach strange females. This may sometimes reflect uncertainty about the identity of the signaller; but usually their very hesitant and cautious behaviour, so unlike their approach to their own mothers, indicates that they are aware of approaching a potentially hostile strange female. Presumably they approach nevertheless because they have a slight chance to obtain milk even from strangers ( 3 observations). However, stealing milk is not sufficient to keep alive a pup which has lost its mother. All such starving pups tried to sneak a little milk, crawling silently up to sleeping females or approaching incoming calling females. But of 31 orphaned pups none obtained sufficient milk to keep its weight or to survive for a month.

\section{The sea lion.}

The observational evidence for individual recognition of pups by their mothers has been presented by Peterson \& Bartholomew (1967) for the California sea lion ( $Z$. c c californianus), and very little needs to be added for the Galápagos subspecies. Sea lion mothers call much more than fur seal females during the pup's first days of life. After giving birth, some mothers are relatively tolerant, others become very aggressive, biting and tossing any strange pup that happens to come close.

When returning from a foraging trip mothers of pups less than a month old often search large areas and keep calling for a long time if they cannot find their pups. Mothers of young of about 6-12 months or older do not normally search for their young but will respond with PACs once they hear them. 
When a mother is calling from a distance, of many pups in a playgroup usually this mother's pup responds soonest and most strongly. Pups and frequently also yearlings tend to approach the sea lion closest by. In doing so they often deviate for more than $90^{\circ}$ from the direction of their calling mother. This may indicate poor directional hearing in air or, perhaps more likely, it points to the overwhelming importance of visual stimuli in orienting the acoustically released searching behaviour.

If a strange female answers to the calling of a lone pup it approaches her slowly and hesitantly with neck far outstretched, always ready to retreat. If rebuffed, older young (about 3 weeks) retreat quickly while younger pups may persist for a while in their attempts to get accepted. But they are never successful in approaches to active females. Of the 42 marked pups, observed for up to 2 months continuously on Santiago, none was ever seen nursing from a strange female. Pups trying to steal milk behave as described above for fur seal pups. I only once observed a pup (on Española) sneaking up to a sleeping female and actually suckling form it for about $2 \mathrm{~min}$ before the female woke and chased it away. Three pups were observed to starve to death after their mothers had disappeared.

These observations confirm that mothers of the Galápagos fur seal and sea lion nurse only their own pup and after a very brief learning (or imprinting? BARTHOLOMEW, 1959) period cannot be cheated about its identity. The differences in the behaviour of pups towards their own mothers and towards strangers, and their prompt reaction to the PACs of their mothers from a distance, suggest that the mother too is individually recognized.

Mother and pup calls used to achieve and maintain contact.

Fur seal mothers, and less strikingly sea lion mothers as well, use two different although intergrading types of calls for achieving and maintaining contact with their young. The extreme forms of these calls are given under clearly different circumstances.

The first type, in the literature generally termed 'Pup Attraction Call' (PAC) (BARTHolomew, 1959), is mainly used to attract the pup from a distance, often before visual contact has been established or after it has been lost. PACs of Galápagos fur seals are composed of two usually quite distinct parts. Part one shows numerous more or less distinct parallel frequency bands with little amplitude difference. Highest amplitude frequencies lie between 700 and $1500 \mathrm{~Hz}$. The second part of the call displays fewer high amplitude bands in the range of $650-900 \mathrm{~Hz}(\overrightarrow{\mathrm{x}}=800$ 


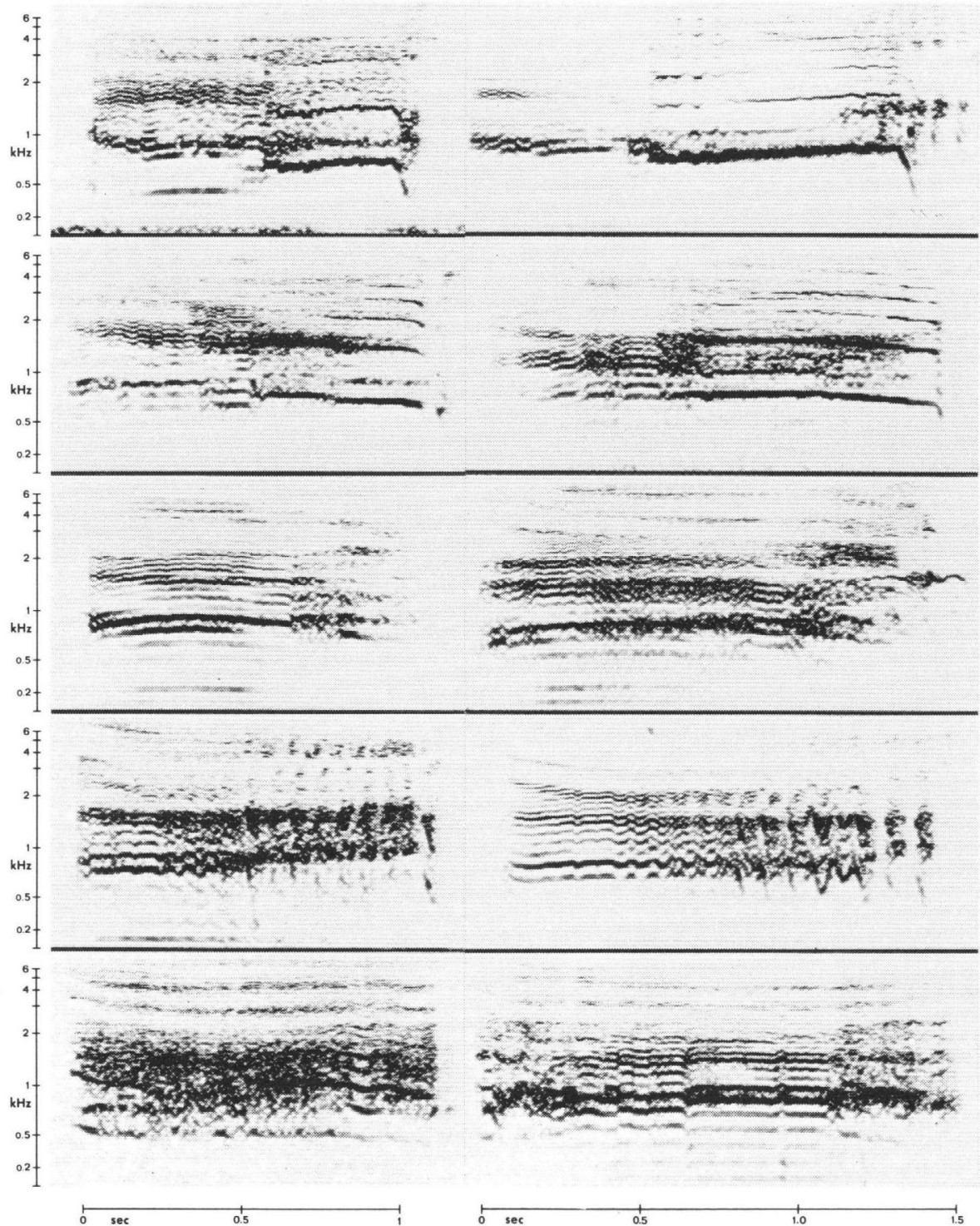

Fig. 2. Each row shows the Pup Attraction Calls (PAC) of a different Galápagos fur seal female. See text for details. 

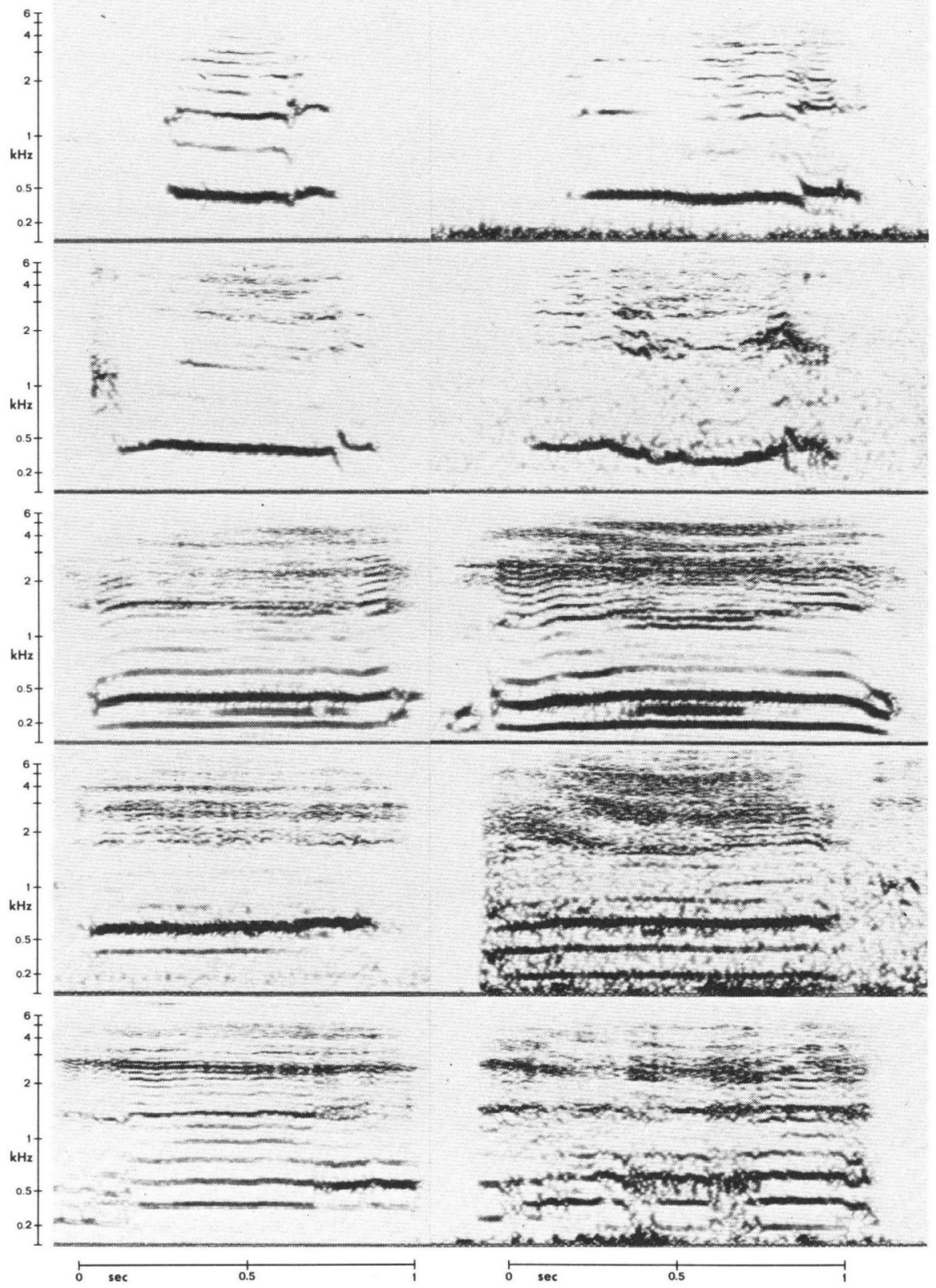

Fig. 3. Each row shows two PACs of a different Galápagos sea lion female. See text for details. 
$\mathrm{Hz}, \mathrm{N}=11)$ and $1400-2000 \mathrm{~Hz}(\overline{\mathrm{x}} \approx 1700 \mathrm{~Hz}, \mathrm{~N}=11)$ (see Fig. 2). These may either be almost unmodulated, with a drop in frequency towards the end of the call, or may be tremolo-like in a few females (compare Fig. 2, 2nd and 4th row).

To obtain an objective measure of differences between individuals, the two most dominant frequencies in 6-13 PAC-sonagrams of 11 different females were compared pairwise. Out of the 55 possible pair combinations only 8 were not significantly different $(\mathrm{p}<0.05$; Mann-Whitney U-Test, two tailed).

PACs of sea lions have their dominant lower frequency between 300 and $600 \mathrm{~Hz}(\overline{\mathrm{x}}=500 \mathrm{~Hz}, \mathrm{~N}=10)$ and a somewhat less dominant frequency between 1000 and $1700 \mathrm{~Hz}(\overline{\mathrm{x}} \approx 1400 \mathrm{~Hz}, \mathrm{~N}=10)$ (Fig. 3). Differences between the PACs of 10 sea lion females were determined as described above. Using this crude method of measurement only 3 of the 45 possible pair combinations were not significantly different.

If such a simple measure as the frequency of the two highest amplitude bands in the PACs allows discrimination between most individuals, then pups clearly have a sufficient physical basis for individual recognition of their mothers' PACs. The human observer can usually easily distinguish the calls of different females. The second type of call mentioned above is given by a female when she is in contact with her pup. Therefore I term it the Pup Contact Call, PCC. Fig. 4 compares PCCs and PACs (2 fur seal

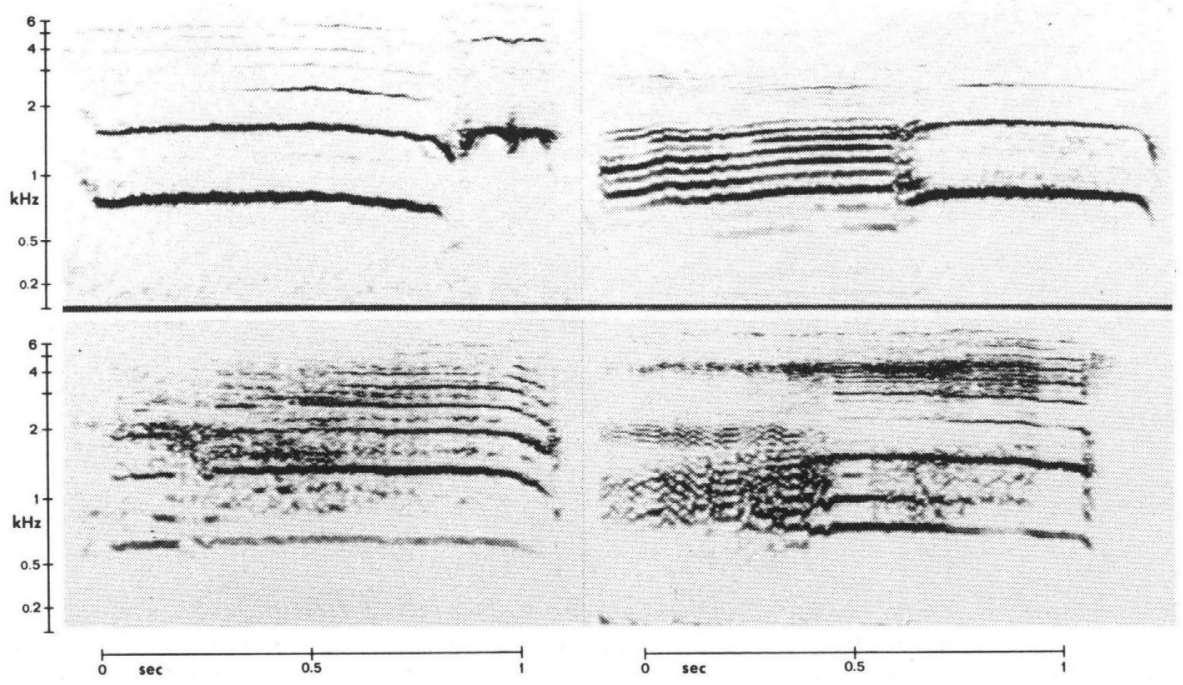

Fig. 4. Comparison of Pup Contact Call (PCC) (left) and PAC (right) in two Galápagos fur seal females. The PCC is similar to the second part of the PAC. 


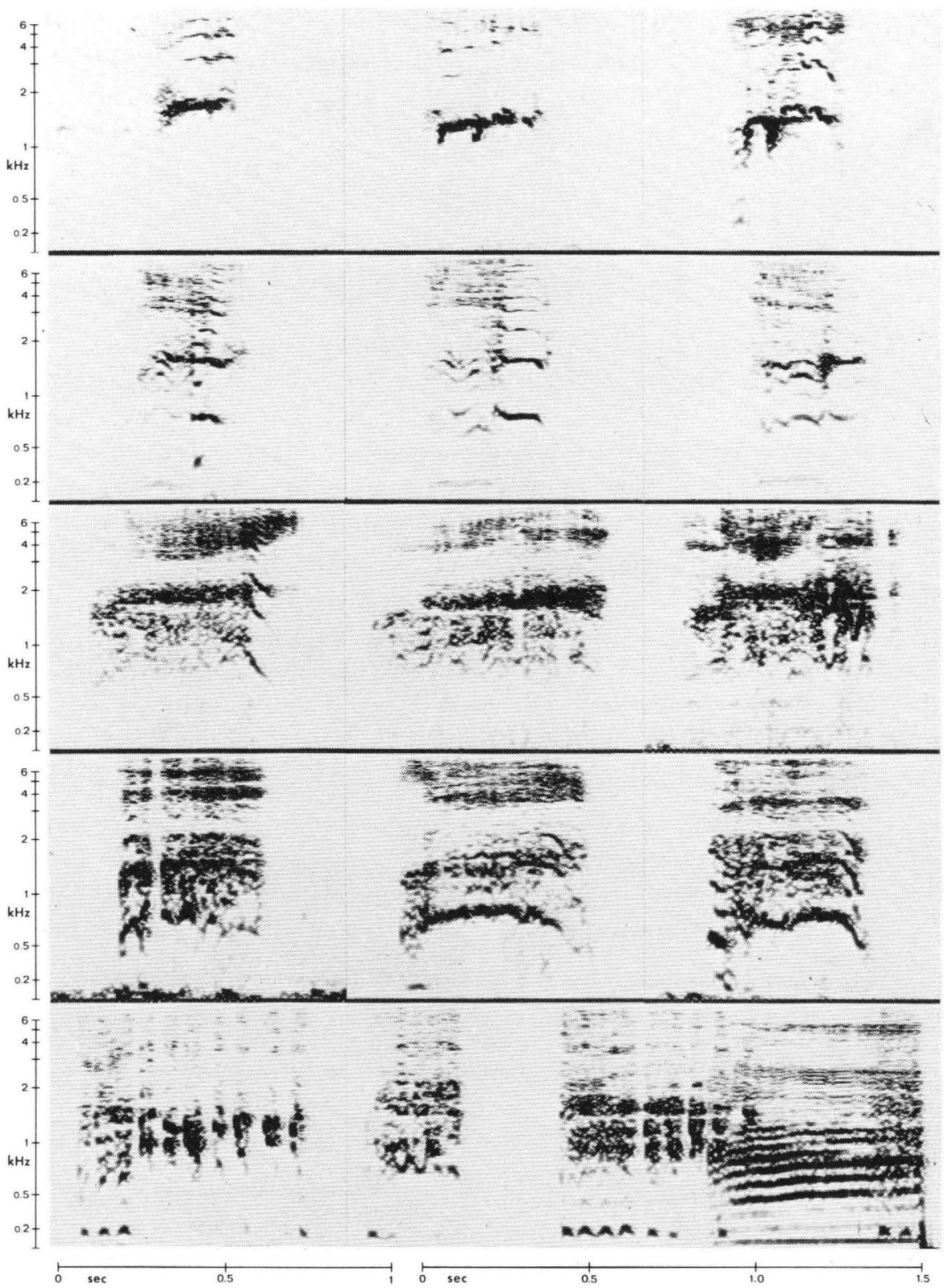

Fig. 5. Calls of Galápagos fur seal pups. Top four rows: Three calls each of four different pups. The three normal bleats of a pup in the fourth row can be compared with the staccato calling of the same pup in the fifth row. Note the low frequency (ca. $0.2 \mathrm{kHz}$ ) part in the staccato call which is missing in normal calls. At the end of the fifth row the calling of the pup merges into its mother's PAC. 
females). The second part of the fur seal PAC with its fewer high amplitude frequency bands appears almost identical with the PCC. Intermediates between PAC and PCC exist. In the Galápagos sea lion PCCs are usually much shorter and of somewhat higher frequency than PACs. For lack of adequate tape-recorded material these differences cannot be demonstrated in sonagrams.

Discrimination between PAC and PCC of a given female is easy for the human, at least for the extreme types of this graded signal. It can be difficult, however, to ascribe a single call of an unknown female to either category because of the interindividual variability of PACs and PCCs.

Pup calls of both species are also individually specific. When searching for their mothers pups bleat. Interindividual variability of the normal bleat is shown in Fig. 5 for fur seal and in Fig. 6 for sea lion pups. This bleat changes into a very rapid staccato calling upon contact with the mother (Fig. 5, lowest two rows). Groups of short syllables are typical for this greeting call.

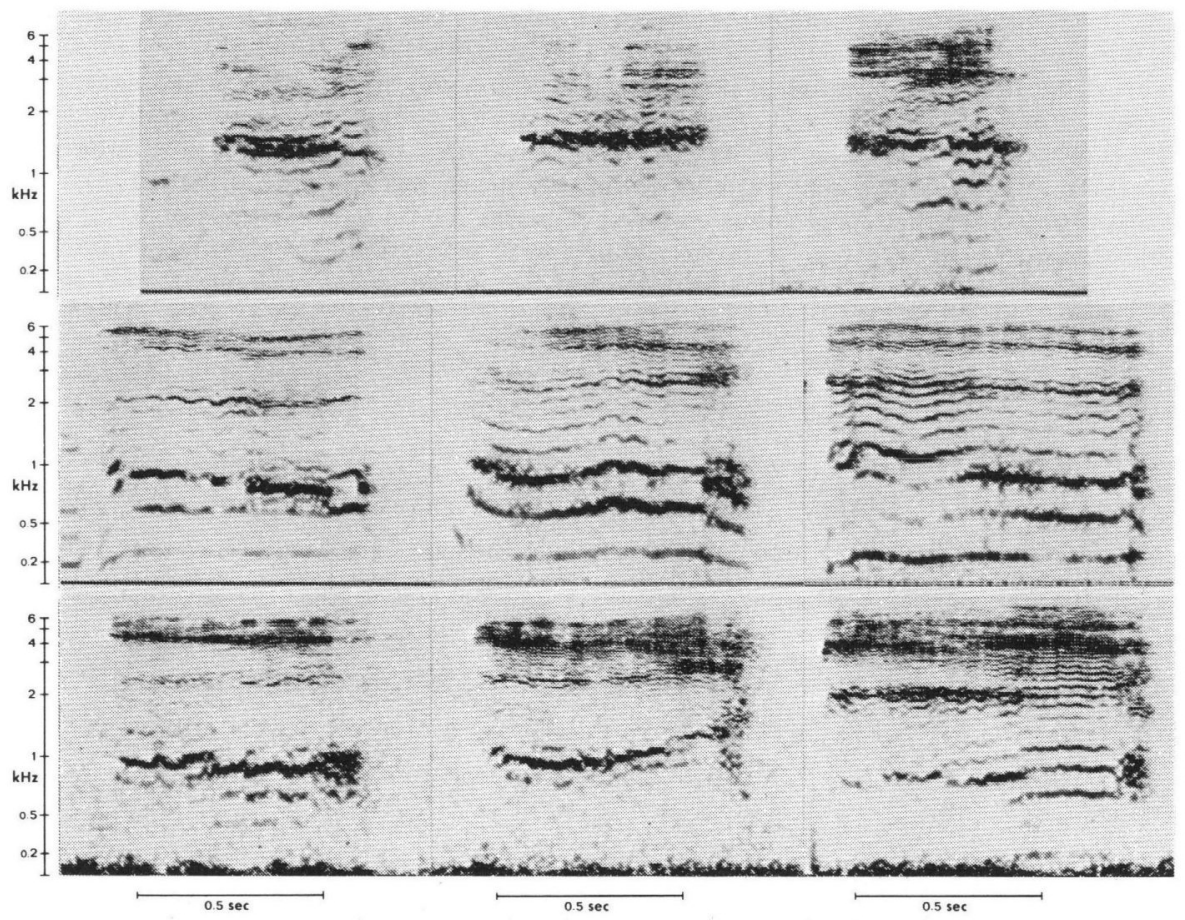

Fig. 6. Calls of Galápagos sea lion pups. Each row shows three calls of a different pup. 


\section{Playback experiments.}

On the basis of the above observations and analyses of calls it was thought that acoustical cues alone should carry sufficient information to enable a pup to discriminate at a distance between its mother and strange females. This hypothesis was tested with experimental playback of the PACs of individually known mothers.

In the original recording wave action sometimes caused considerable background noise. The clearest 5-10 calls of a female were copied on a second tape and this copy was used for the playback experiments. Mothers' voices were played back from the internal loudspeaker of the Uher tape recorder. They were therefore of considerably less volume than the natural calls.

\section{The fur seal.}

Methods.

Young between 10 days and 2 years of age whose mothers had been absent for at least $6 \mathrm{~h}$ were tested. As the fur seal habitat is very irregular, simultaneous choice experiments were impossible, as no equivalent positions at each side of a pup could be found for the two tape recorders. Therefore a pup was presented with either (1) alternating sequences of its mother's and a strange female's PACs (Treatment 1 ) or else (2) pups were tested in a play-group of animals of about equal age, with these animals acting as control (Treatment 2). Tape recorders were manually controlled. Calls were presented from a distance of 2-5 $\mathrm{m}$ and were always separated by pauses of $15-20 \mathrm{sec}$. The number of presentations varied because pups sometimes disappeared under boulders or began interactions with older animals. An additional person recorded which pup(s) if any responded to the playback. A response was scored as positive if the playback induced calling or an approach of the pup towards the tape recorder within the pause following the presentation. Undirected locomotion in a previously resting pup was scored only for pups of 10-12 days old. Distances between tape recorder and pup were readjusted every 5-10 presentations. In most experiments it was also recorded how often the animal responded to a single playback call.

\section{Results.}

Figure 7 gives the results of 4 Treatment 1 experiments with very young pups (10-12 days old). Three of these pups discriminated between the PACs of their mother and a strange female. In Fig. 7A the PACs of the mother of one young were used as the PACs of the strange female for the other pup and vice versa. As both pups preferred their own mother's PACs significantly, this demonstrates that differences in loudness of calls or in the quality of tape recordings could have played only a minor role in determining response strength. In the experiments with Treatment 2, only the pup whose mother's PACs were played back responded strongly, while the other pups almost never reacted (Fig. 8). This again shows that volume of calls or quality of tape recordings can only be of minor importance. 

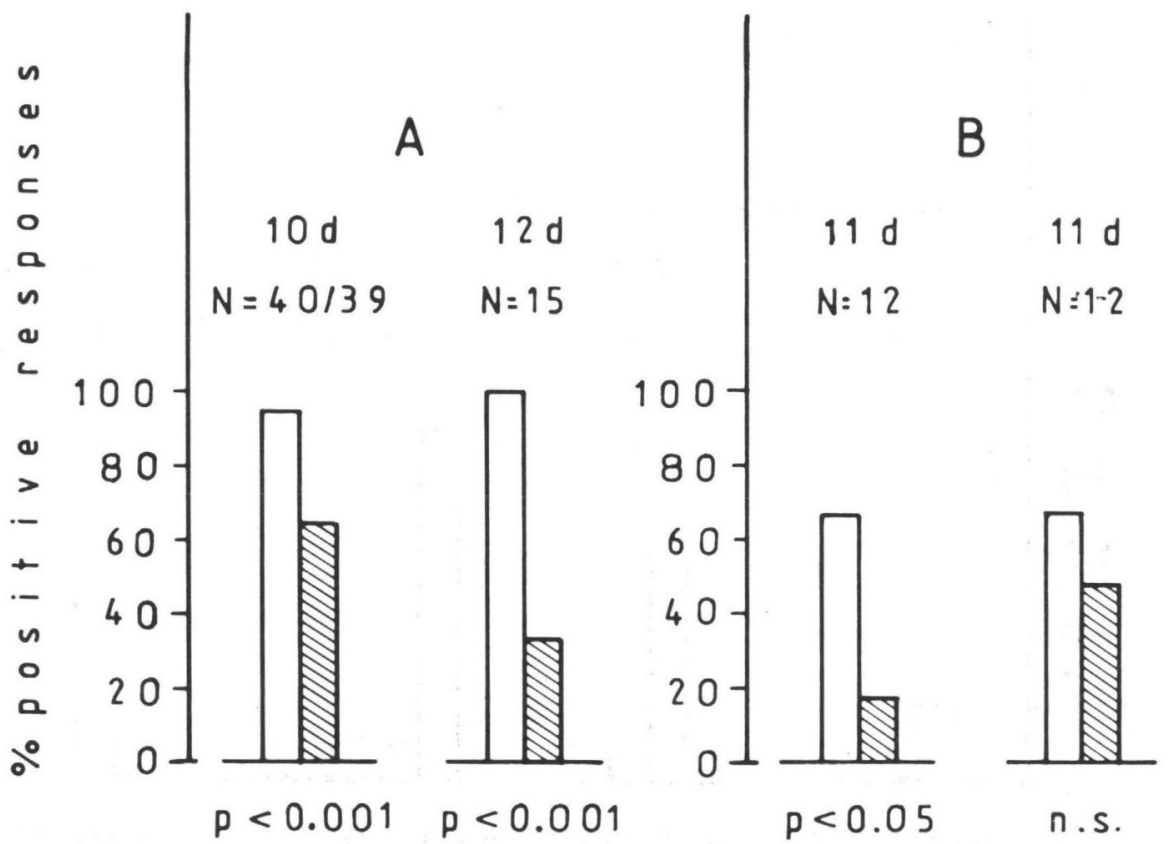

Fig. 7. Alternating playback of two females' PACs to one fur seal pup. White column: Reactions to mother's PACs. Hatched column: Reactions to strange female's PACs. Above the graph are age of pup $(\mathrm{d}=\mathrm{day})$ at time of testing and no. of presentations. If 2 numbers are given, the first corresponds to the left column, the second to the right. Below the columns significance of difference between reactions to mother versus stranger. (Chisquare test or Fisher exact probability test, depending on $\mathrm{N}$; calculated with absolute numbers). A: Two different pups tested in a crosswise experimental design. B: Two different pups tested with the PACs of different females.

The pups in Fig. 7, tested with Treatment 1, responded much more to the strange female's PACs than the control pups in the experiments shown in Fig. 8 (Treatment 2). This difference in specificity is presumably due to the fact that Treatment-1-pups had been stimulated into calling by their mothers' PACs when they heard those of the strange female, while control pups in Fig. 8 had not heard a PAC of their own mothers.

Figure 9 shows for 2 pups, tested repeatedly, that this specificity of response lasts over the whole period of dependence of the young. Even the 2-year-olds still responded strongly to their mothers' calls.

Neither the percentage of positive reactions, nor the number of approaches per positive reaction, nor the number of calls per positive reaction correlated significantly with age of the young. This suggests that the 


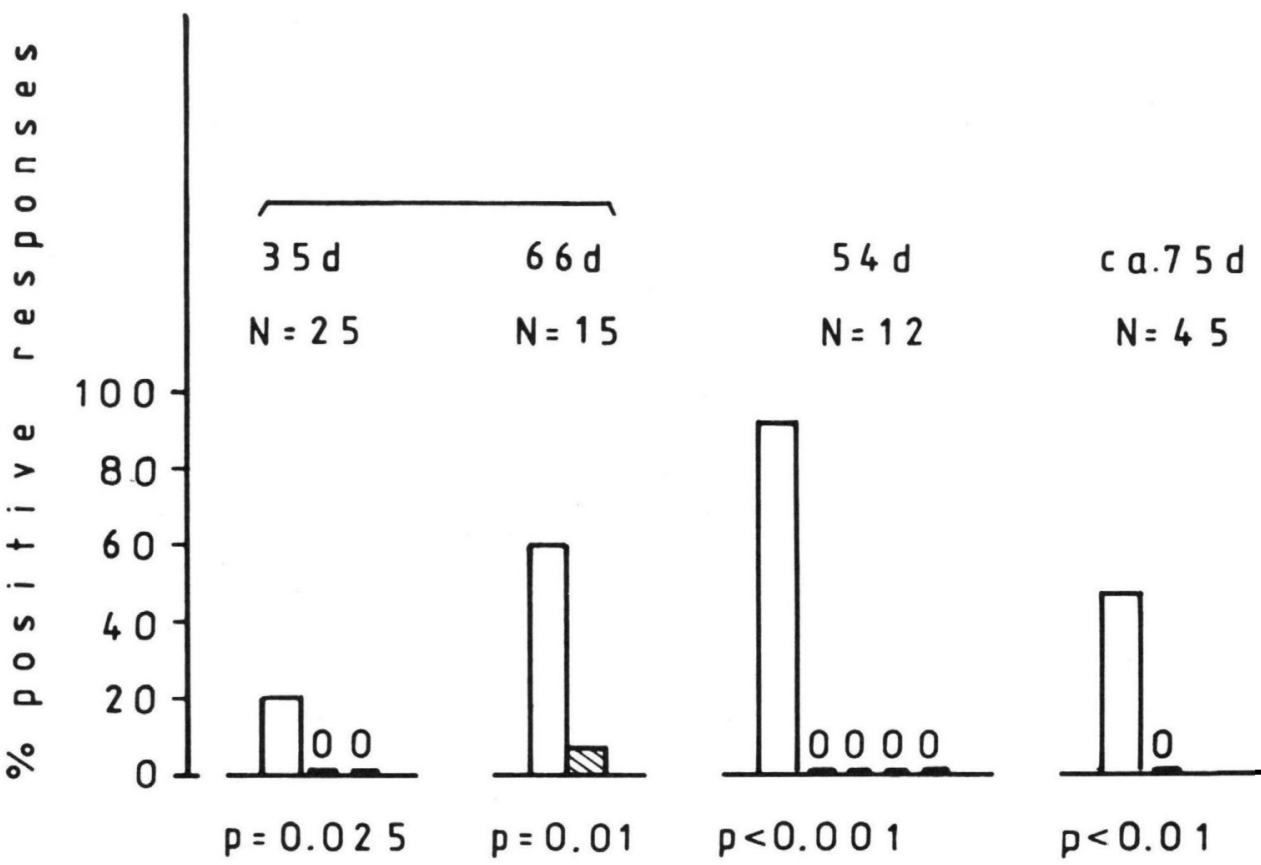

Fig. 8. Playback of one female's PACs to two or more pups in a group; one pup (white column) is this female's pup. The hatched column or black lines (right of white column) show reactions of strange pups of about equal age to the same presentations. The bracket indicates experiments made on the same pup at different ages. Further symbols as in Fig.

specificity of the response to the mother's PACs has developed completely by the age of 10 days. However, pups of about 6 months and the immatures of 2 years of age approached over much larger distances than small pups, were more persistent in their searching, and kept calling and searching after the end of the playback. Also they approached the loudspeaker more directly, but once near it they tended to investigate all fur seals nearby, indicating the importance of visual stimuli in orienting the searching behaviour. At this age the contribution of the young to the mother-young reunion has become essential, because these older young range far over the colony.

The great variability in response strength presumably depends on factors such as time of mother's absence, playing, resting, state of hunger, and other motivational factors not measured in these experiments. 

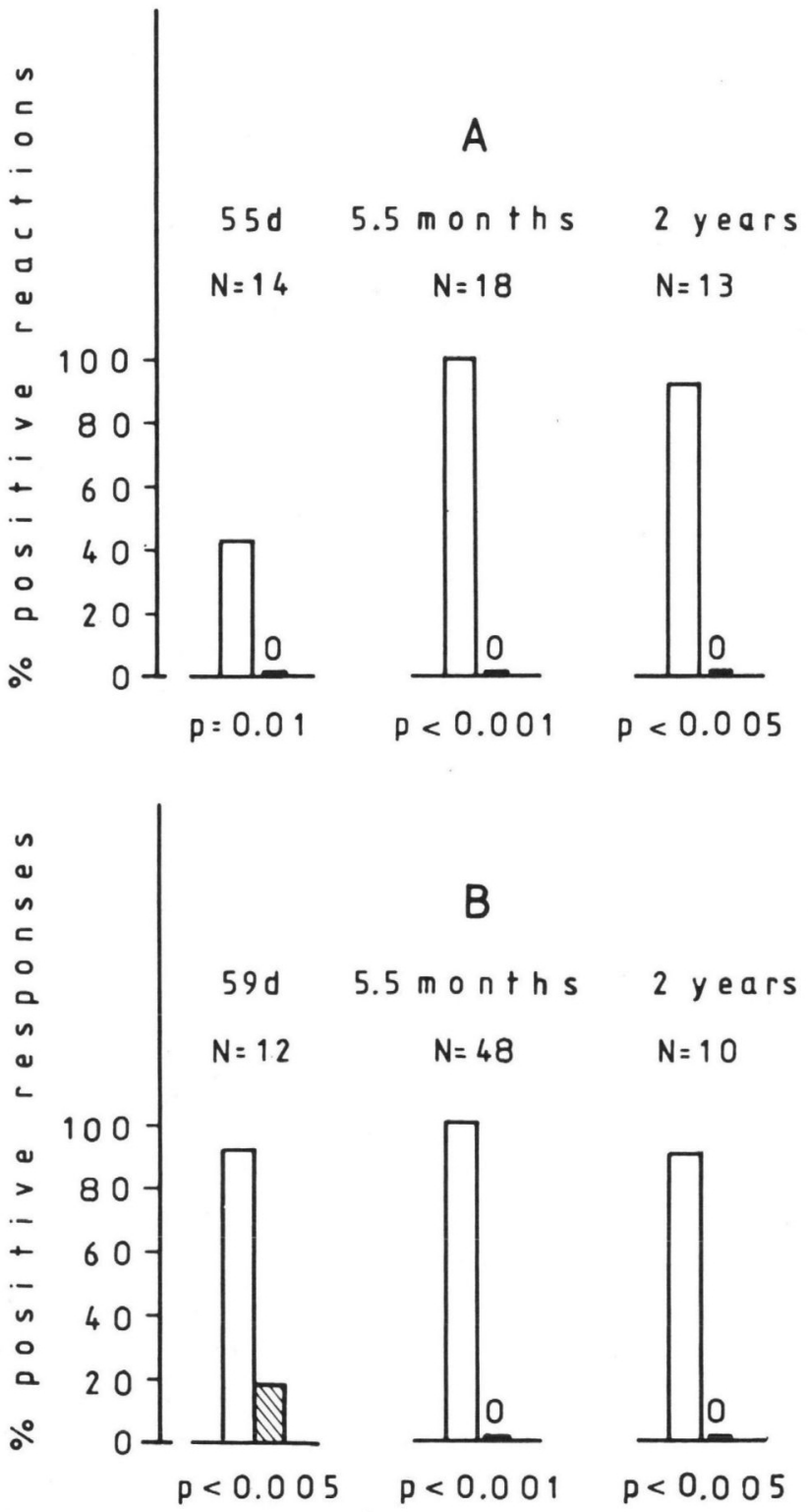

Fig. 9. Playback of PACs to two young fur seals at different ages. A: Reactions of pup $8 / 77$ at three different ages (white columns) and of another young of about equal age (right of white column). B: The same for pup 10/77. The other young (right of column) at age 59 days and 2 years is pup 8/77 of part A. Symbols as in Fig. 7. 


\section{The sea lion.}

Methods.

Pups of 10-31 days of age were tested with alternating presentations of their mother's and a strange female's PACs. For the playback two persons, with a tape recorder each, positioned themselves about $5 \mathrm{~m}$ from the resting or playing pup so that access to both tape recorders was equally easy. This presented no problem on the flat sand beaches where sea lions live. Calls were presented with pauses of 15-30 sec. Rarely, pauses between presentations had to be lengthened, as the test pup did not stop calling after $30 \mathrm{sec}$. After 5-10 presentations the voices of mother and strange fernale were played back from the other tape recorder, to avoid side bias. Distances between pup and the two tape recorders were readjusted to about $5 \mathrm{~m}$ at this time. Series of 3 or 5 calls of one female, alternating with series of 3 or 5 calls of the other, were sometimes presented after 10-15 presentations of single calls. Calls in these series were separated by pauses of $2-5 \mathrm{sec}$ with a 15-30 sec pause after every series. The pup's responses were recorded as described for the fur seal experiments. Mother recognition was always tested crosswise, i.e. the strange female for one pup was the mother of the other test pup and vice versa.

Results.

Figure 10 shows the responses of 8 different sea lion pups to the playback of PACs. One pup 10 days old did discriminate between its mother's voice and that of a strange female (Fig. 10A). Two other 10-day-old pups did not discriminate significantly, but were shown to react equally indiscriminately at the age of 19 or 25 days (Fig. 10C and D), when 4 other pups of similar ages were highly discriminating (Fig. 10). Possible reasons for the failure of these two pups are discussed below. In the range of ages tested (10-31 days) these few experiments did not demonstrate any improvement in the specificity of the pups' responses with age. If calling was released at all by a played back PAC, then all 8 pups gave more calls in response to the mother's PAC than to that of a strange female (Binomial test; $p=0.02$ ). Most pups responded to the PAC's of strange females. This demonstrates the arousing effect of PACs. However, pups appear to habituate more rapidly to the PACs of strange females than to those of their mothers. Three pups, 10,17, and 31 days old, which discriminated between the calls, quit answering strange PACs in the last 11,10 , and 4 presentations, respectively, while still strongly responding to their mothers' PACs.

The two pups which showed no clear discrimination between the PACs of their mothers and of the strange female had been handled a lot for weighing before these test. They appeared slightly afraid of the experimenters. They, as all other pups, responded with more calls in answer to their own mothers than to the strange females. Also, both pups looked more often towards the tape recorder playing back their mother's voice than to the other one; but this could not be recorded sufficiently accurately to serve as a basis for a decision. All this makes it likely that even these 

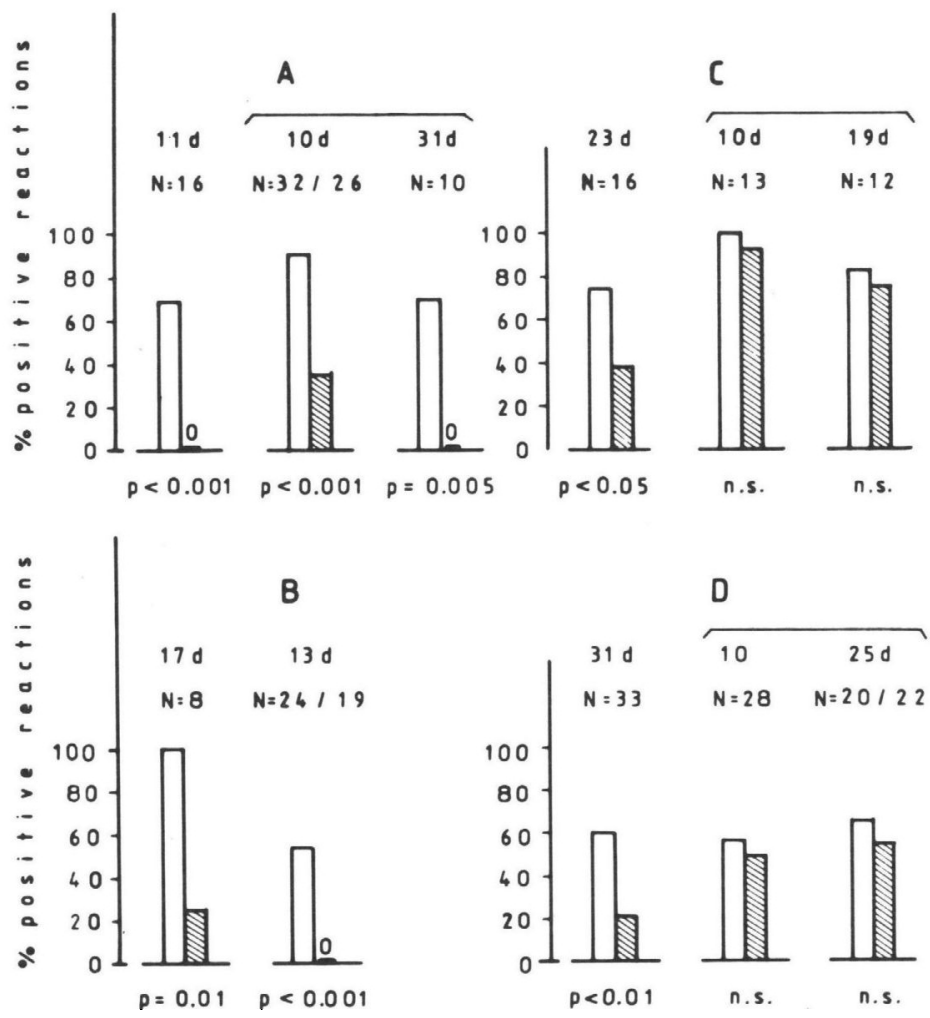

Fig. 10. Sea lion playback experiments. One group (A, B, C, and D) always shows pups which were tested crosswise with the PACs of the same two females (see methods). White columns: Reaction to mother's PACs; Hatched columns: Reactions to strange female's PACs. Brackets indicate the same pups tested at two different ages. Further symbols as in

Fig. 7.

pups made a distinction between the two types of PACs which, however, went undetected with the measurement taken. In both cases the other pup in these crosswise experiments discriminated significantly between these same calls (Fig. 10C, D).

\section{DISCUSSION}

The playback experiments prove that the PACs of these two species convey sufficient information to allow pups to determine the signaller's identity. Furthermore, PACs presumably function to arouse and roughly orient the pup towards its mother. Orientation is not very accurate however and visual cues play a very important role in directing the pup's final approach. 
Other authors have stated that young pups do not play an active role in mother-pup reunion, without specifying what they mean by 'young'. Only Peterson \& Bartholomew (1976) define 'young' as under 2 months of age. For reasons discussed below it seems unlikely that the discriminatory abilities of pups of other otariid or colonially breeding phocid species should be much poorer than that of the Galápagos species.

Some support for this claim comes from data by TERHUNE et al. (1979) on individual recognition of harp seal (Pagophilus groenlandicus) pups by their mothers. The authors did not take into consideration that their observations may also show recognition of mothers by pups. But according to their Table 1, on activities of animals prior to acceptance or rejection of pups by cows, 18 of the accepted pups were moving and 4 were stationary, whereas of the rejected ones 25 were moving and 22 stationary. These data differ significantly from an assumption of equal behavioural activities of pups when confronted with mothers versus strange females $\left(\chi^{2}=5.25 ; p<0.05\right)$. Therefore mutual recognition between mother and pup in harp seals appears to be a possibility.

Comparison with data from other mammals.

In other mammalian species with precocial young these have been shown to recognize their mothers soon after birth (Shillito, 1975; Sillito \& Alexander, 1975; Lent, 1974; Leuthold, 1977; Espmark, 1971; Tschanz, 1962) and the same is true even for mammals with altrical young (Hansen, 1976; Kolb, 1977, MacFarlane, 1977). But these young follow other females opportunistically if their own mothers are not available (LENT, 1974). This is often interpreted as proof of their inability to discriminate between the mother and a strange female; but in many cases the experimental evidence shows this interpretation to be not true. Also, acceptance of a strange object in a successive choice situation does not necessarily imply lack of discrimination but may rather demonstrate the releasing value of the unfamiliar object (FrANCK, 1966; Trillmich, 1976). The assumption that pups approaching strange females do so because they cannot recognize their mothers is refuted by the experiments described above. Why then do pups approach strange females?

Functional considerations.

The pup.

The individual pup much more often ignores or avoids a strange female than it approaches one; but with the great number of pups in a 
colony one gets the impression that pups approach strangers quite frequently.

The behaviour of some pups in approaches to strange calling females suggests that their approach is caused by an identification error. However, such an error can frequently be corrected before the pup makes contact with the strange female, as the calls of the approaching pup induce the approached female to answer. This provides the pup with a possibility to check on its initial identification and to retreat, if it has made a mistake, without much risk. In this way mother-recognition reduces the frequency of potentially dangerous encounters with strangers.

If the pup has discriminated and nevertheless approaches a strange female, it can choose an appropriate strategy of approach; instead of calling loudly and running up to the female, as it does when approaching its mother, it can sneak up silently and cautiously. Using this strategy the cost (energy and risk) of approaching a strange female may be less than the potential benefit (energy from stolen milk; experience in interactions with hostile adults?).

In elephant seals, pups even have a chance to become adopted. This means the difference between death and survival if they have lost their mother, or much increased growth if they have already been weaned by their own mother (REITER et al., 1978). A few observations on Galápagos sea lion females and a single one on a South American fur seal (ArCtocephalus australis) female hint at the possibility that even otariid pups have a slight chance of being adopted. These females were observed nursing two pups of about equal age simultaneous (pers. obs.) although twin births have never been recorded in any otariid.

\section{The female.}

Only three times were Galápagos fur seal females observed to nurse a strange pup. Two of these females were in oestrus when females generally are much more contact tolerant and none of these females was ever again observed to nurse a strange young. Although other females a few times appeared to make identification errors when approaching strange calling young, they never accepted them after the olfactory check. The same applies for sea lion females.

This specificity is obviously advantageous because if an otariid female were non-discriminating she would necessarily invest in foreign young, thus reducing the milk supply for her own pup. FoGDen (1971) has shown that under disturbed conditions in a Grey seal (Halichoerus grypus) colony 
a lot of inconsistent (i.e. strange female-pup) nursing occurs. But although the inconsistently-sucking pups were nursed by up to 10 different females and suckled more frequently than pups nursed only by their own mothers, the latter were suckling for a longer total time and appeared much healthier and fatter at weaning than the former.

Mechanisms of pup recognition in pinniped females.

Individual recognition of young in birds depends on nest density and mobility of young. The use of individual recognition mechanisms by parents can be demonstrated from the time when the probability of confusing own young with foreign young increases rapidly (Miller \& EMLEN, 1975). It is tempting to apply this argument to pinnipeds.

In ice-breeding phocid seals exclusive maternal care for own offspring can usually be ensured if mothers are faithful to the site of birth, because density of seals on the ice is relatively low and mobility of pups limited, so that confusion of young is unlikely. Also phocid females provision their young for a few weeks only and are therefore not forced to be absent a lot for foraging. Such a site-dependent recognition system must fail in a dense otariid colony where females frequently undertake foraging trips and consequently many young are left unattended at any time. Colonial breeding thus puts a high premium on the development and use of an individual recognition mechanism to ensure correct placement of maternal care. In phocid seals breeding in dense colonies on land (grey seals and elephant seals) females individually recognize their pups (Petrinovich, 1974; Fogden, 1971). However, their recognition mechanism appears to be less reliable than in otariid seals, resulting in more inconsistent nursing (Fogden, 1971; Reiter et al., 1978). One possible reason for this greater inconsistency may be that the animals have not yet had very much time to adapt their recognition system to the habit of breeding on land in dense colonies, as this social structure may have developed since the last ice age only (Stirling, 1975). Elephant seal females may even benefit from nursing strange young if they have lost their own immediately after birth. Le Boeur et al. (1972) found that females which had not nursed a young did not copulate that year, and thus may have lost a whole year of their reproductive life, whereas females which had nursed at least several days were observed copulating.

\section{SUMMARY}

Field observations on Galápagos fur seals and sea lions indicate mutual recognition between mother and pup. High calling activity and intensive interactions of mother and pup 
immediately after birth appear to establish recognition within the first few hours (mother) or days (pup) of birth. Females of both species nurse exclusively their own young and reject strange ones, sometimes very aggressively. The prompt reactions of pups to their mothers' Pup Attraction Calls (PACs) suggest that the mother too is individually recognized. The analysis of the PACs of mothers and the bleats of pups shows that interindividual variability of calls provides a sufficient basis for individual recognition in both species. Playback experiments with PACs of fur seals and sea lions show that pups (10 days to 2 years old) can discriminate between their mothers' and strange females' PACs. Mother recognition reduces the frequency of dangerous encounters of pups with strange females or allows pups to approach strangers especially careful, thus reducing the risk of injury. Only by means of individual recognition can females in crowded otariid rookeries limit maternal investment to their own offspring. The mechanism of individual recognition in dispersed, ice-breeding phocids and colonially breeding otarid seals may be different.

\section{REFERENCES}

Bartholomew, G. A. (1959). Mother-young relations and the maturation of pup behavior in the Alaska fur seal. - Anim. Behav. 7, p. 163-171.

Espmark, Y. (1971). Individual recognition by voice in reindeer mother-young relationship. Field observations and playback experiments. - Behaviour 40, p. 295-301.

Fogden, S. C. L. (1971). Mother-young behaviour at Grey seal breeding beaches. J. Zool., Lond. 164, p. 61-92.

Franck, D. (1966). Möglichkeiten zur vergleichenden Analyse auslösender und richtender Reize mit Hilfe des Attrappenversuchs, ein Vergleich der Successiv- und Simultanmethode. - Behaviour 27, p. 150-159.

Hansen, E. W. (1976). Selective responding by recently separated juvenile rhesus monkeys to the calls of their mothers. - Develop. Psychobiol. 9, p. 83-88.

KolB, A. (1977). Wie erkennen sich Mutter und Junges des Mausohrs, Myotis myotis, bei der Rückkehr vom Jagdflug wieder? - Z. Tierpsychol. 44, p. 423-431.

Laws, R. M. (1956). The elephant seal (Mirounga leonina Linn.) II. General, social and reproductive behaviour. - F.I.D.S. Sci. Rep. No. 13, pp. 88.

Le Boeuf, B. J., Whiting, R. J. \& Gantt, R. F. (1972). Perinatal behavior of northern elephant seal females and their young. - Behaviour 43, p. 121-156.

- $\&$ BRiggs, K. T. (1977). The cost of living in a seal harem. - Mammalia 41, p. $167-195$.

Lent, P. C. (1974). Mother-infant relationships in ungulates. - In: Proc. Int. Conf. Behav. of Ungulates and its relation to management (V. GeIsT \& F. WALtER, eds), Unwin Brothers, London 1974, p. 14-55.

Leuthold, W. (1977). African ungulates. - Springer Verlag. Berlin-Heidelberg-New York.

MacFarlane, A. (1977). The psychology of childbirth. - Fontana/Open Books, London.

MaNab, A. G. \& Crawley, M. C. (1975). Mother and pup behaviour of the New Zealand fur seal, Arctocephalus forsteri (Lesson). - Mauri Ora 3, p. 77-88.

Miller, D. E. \& EMLEN, Jr. J. T. (1975). Individual chick recognition and family integrity in the ring-billed gull. - Behaviour 52, p. 124-144.

Peterson, R. S. \& Bartholomew, G. A. (1967). The natural history and behavior of the California sea lion. - Spec. Publ. 1, The American Society of Mammalogists, pp. 79.

Petrinovich, L. (1974). Individual recognition of pup vocalisation by northern elephant seal mothers. $-Z$. Tierpsychol. 34, p. 308-312.

Rand, R. W. (1967). The Cape fur seal (Arctocephalus pusillus) 3. General behaviour on land and at sea. - Investl. Rep. Div. Fish. Un. S. Afr. No. 60, pp. 39. 
Reiter, J., Stinson, N. L. \& Le Boeuf, B. J. (1978). Northern elephant seal development: the transition from weaning to nutritional independence. - Behav. Ecol. Sociobiol. 3, p. 337-367.

Sandegren, F. E. (1970). Breeding and maternal behavior of the Steller sea lion (Eumetopias jubata) in Alaska. - Thesis, Univ. of Alaska.

Shillito, E. E. (1975). A comparison of the role of vision and hearing in lambs finding their own dams. - Appl. Anim. Ethol. 1, p. 369-377.

- - \& Alexander, G. (1975). Mutual recognition amongst ewes and lambs of four breeds of sheep (Ovis aries). - Appl. Anim. Ethol. 1, p. 151-165.

Stirling, I. (1975). Factors affecting the evolution of social behaviour in the pinnipedia. - Rapp. P.-V. Réun. Cons. Int. Explor. Mer. 169, p. 205-212.

Terhune, J. M., Terhune, M. E. \& Ronald, K. (1979). Location and recognition of pups by adult female harp seals. - Appl. Anim. Ethol. 5, p. 375-380.

Trillmich, F. (1976). Recognition of the individual nesting box in budgerigars, Melopsittacus undulatus Shaw (Aves, Psittacidae). - Z. Tierpsychol. 42, p. 1-11.

- - Mohren, W. (1981). Effects of the lunar cycle on the Galápagos fur seal, Arctocephalus galapagoensis. - Oecologia 48, p. 85-92.

Tschanz, B. (1962). Über die Beziehung zwischen Muttertier und Jungen beim Mufflon (Ovis aries musimon Pall.). - Experientia 18, p. 187-190.

\section{ZUSAMMENFASSUNG}

Freilandbeobachtungen an Galápagos Seebären und Seelöwen weisen auf gegenseitiges individuelles Erkennen zwischen Mutter und Jungtier hin. Unmittelbar nach der Geburt rufen Mutter und Jungtier sehr viel und interagieren besonders intensiv. Die Mutter lernt so ihr Junges bereits nach wenigen Stunden zu erkennen, das Junge die Mutter nach wenigen Tagen. Weibchen beider Arten säugen ausschließlich ihr eigenes Junges und weisen fremde mitunter sehr aggressiv ab. Dabei können Junge zu Tode kommen. Die Lockrufe der Weibchen und die Antwortrufe der Jungen beider Arten variieren interindividuell sehr. Dies stellt eine ausreichende Basis für individuelles Erkennen dar. In Vorspielexperimenten mit Lockrufen von Müttern beider Arten unterschieden die Jungen (im Alter zwischen 10 Tagen und 2 Jahren) fast ausnahmslos zwischen den Lockrufen der Mutter und denen fremder Weibchen. Diese Unterscheidungshähigkeit hilft den Jungen fremde Weibchen zu vermeiden oder sich solchen Weibchen besonders vorsichtig annähern zu können. Dic Weibchen können durch individuelles Erkennen ihres eigenen Jungen ihre Brutpflege ausschließlich auf diese beschränken. Die Mechanismen des individuellen Erkennens sind bei verstreut auf dem Eis sich fortpflanzenden Hundsrobben (Phocidae) möglicherweise andere als bei Ohrenrobben (Otariidae), die sich in dichten Kolonien an Land fortpflanzen. 